\title{
Verumontanum Mucosal Gland Hyperplasia
}

National Cancer Institute

\section{Source}

National Cancer Institute. Verumontanum Mucosal Gland Hyperplasia. NCI Thesaurus.

Code C63796.

\begin{abstract}
A benign microacinar proliferation occurring exclusively in the verumontanum and adjacent posterior urethra where the ejaculatory ducts and utricle empty into the urethra. Crystalloids and intraluminal mucin are usually absent, but; intraluminal corpora amylacea are often present. The lining epithelium typically consists of bland cuboidal to columnar luminal cells with underlying basal cells.
\end{abstract}

